\title{
Unmet Needs for Ancillary Services Among Hispanics/Latinos Receiving HIV Medical Care — United States, 2013-2014
}

\author{
Lauren C. Korhonen, MSPH${ }^{1,2}$; Nicholas P. DeGroote, MPH ${ }^{1,2}$; R. Luke Shouse, MD ${ }^{1}$; Linda A. Valleroy, PhD ${ }^{1}$; Joseph Prejean, PhD ${ }^{1}$; Heather Bradley, PhD ${ }^{1}$
}

The prevalence of diagnosed human immunodeficiency virus (HIV) infection in Hispanics/Latinos in the United States is more than twice as high as the prevalence among non-Hispanic whites (1). Services that support retention in HIV medical care and assist with day-to-day living, referred to here as ancillary services, help persons living with HIV access HIV medical care, adhere to HIV treatment, and attain HIV viral suppression. The needs for these ancillary services among Hispanics/Latinos are not well described (2). To obtain nationally representative estimates of and reasons for unmet needs for such services among Hispanic/Latino adults receiving outpatient HIV medical care during 2013-2014, CDC analyzed data from the Medical Monitoring Project (MMP). The analysis found that Hispanics/Latinos in all age and sexual orientation/behavior subgroups reported substantial unmet needs, including $24 \%$ needing dental care, $21 \%$ needing eye or vision care, $15 \%$ needing food and nutrition services, and $9 \%$ needing transportation assistance. Addressing unmet needs for ancillary services among Hispanics/Latinos living with HIV might help increase access to HIV care, improve health outcomes, and reduce health disparities.

MMP used a three-stage sample (states and territories, facilities, patients); response rates at each stage were 100\%, 85\%, and $55 \%$, respectively. Data were collected using face-to-face or telephone interviews conducted during June 2013-May 2015. Data were weighted for unequal selection probabilities and nonresponse (3).

Ethnicity was self-reported; Hispanic/Latino participants could be of any race. Sexual orientation/behavior was defined by gender of participants and their sex partners or, if no sexual activity was reported, by participants' sexual orientation. Unmet needs for ancillary services were defined as services that participants reported needing, but not receiving during the 12 months before the interview. The prevalence of unmet needs for Hispanics/Latinos receiving outpatient medical care was estimated overall and, for select services, stratified by age and sexual orientation/behavior using chi-square tests to make statistical comparisons between strata. Services were selected for further analysis based on how often they were reported as unmet needs here and in previous studies. For each of these services, participants' primary reasons for unmet needs were described.
The most prevalent unmet needs for ancillary services among Hispanics/Latinos receiving outpatient HIV medical care were for non-HIV medical care services. An estimated 24\% had an unmet need for dental care and $21 \%$ had an unmet need for eye or vision care (Figure). Among HIV support services examined, the most prevalent unmet need was for HIV peer group support (7\%). Among subsistence services (services that help persons meet their basic needs), the most prevalent unmet need was for food or nutrition services (15\%); $9 \%$ had an unmet need for transportation assistance, and $8 \%$ had an unmet need for shelter or housing services.

Hispanics/Latinos aged 18-29 years and 30-39 years had a higher prevalence of unmet needs for both shelter or housing services and HIV peer group support than those aged $\geq 50$ years (Table 1). Hispanics/Latinos aged 30-39 and 40-49 years had a higher prevalence of unmet needs for food or nutrition services than those aged $\geq 50$ years. Hispanics/Latinos aged 30-39 years had a higher prevalence of unmet need for dental care $(31 \%)$ than those aged $\geq 50$ years $(21 \%)$. Unmet needs for eye or vision care, transportation assistance, and mental health care did not differ significantly by age. Hispanic/Latino men who have sex with only women had a higher prevalence of unmet needs for transportation assistance services, and a lower prevalence of unmet needs for HIV peer group support and mental health care, compared with Hispanic/Latino men who have sex with men. Unmet needs for other services did not differ significantly by sexual orientation/behavior category.

Over $40 \%$ of Hispanics/Latinos with an unmet need for transportation assistance, food or nutrition services, or HIV peer group support did not know how to get these services (Table 2). Approximately one quarter of Hispanics/Latinos with an unmet need for shelter or housing services, mental health care, or eye or vision care did not know how to get these services (25\%, 25\%, and 22\%, respectively). Twenty-eight percent of Hispanics/Latinos with an unmet need for shelter or housing services, $21 \%$ with an unmet need for transportation assistance, and $15 \%$ with an unmet need for food or nutrition services were ineligible for, perceived themselves to be ineligible for, or were denied these services. Less than $20 \%$ of Hispanics/ Latinos with an unmet need for dental care or eye or vision care reported money/insurance issues as the reason for not receiving the service (16\% and $14 \%$, respectively). 
FIGURE. Unmet and met needs for ancillary services* among Hispanics/Latinos receiving outpatient human immunodeficiency virus (HIV) medical care - Medical Monitoring Project, United States, 2013-2014

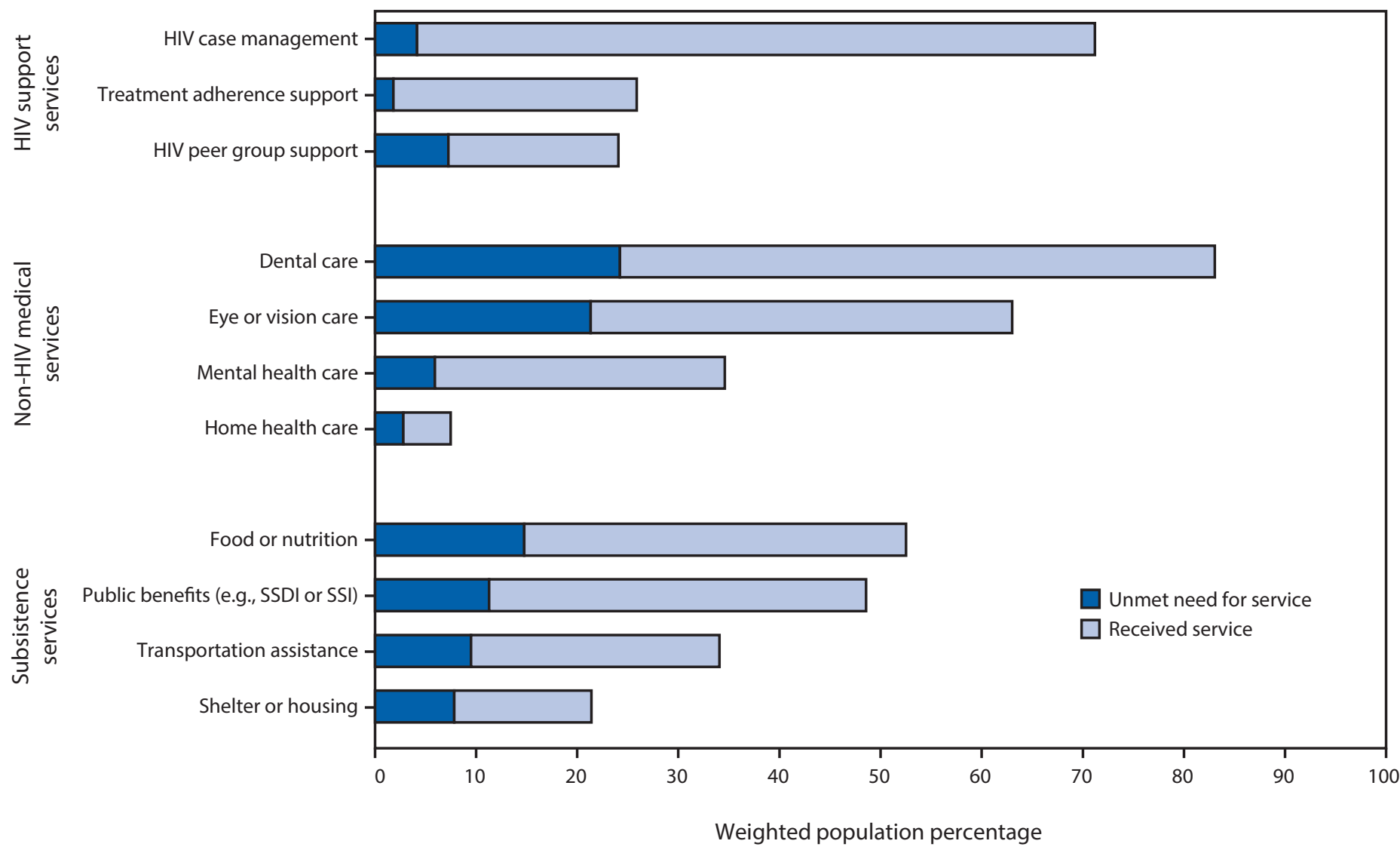

Abbreviations: SSDI = Social Security Disability Income; SSI = Supplemental Security Income.

* Ancillary services are defined as services that support retention in primary HIV medical care and assist with day-to-day living.

\section{Discussion}

During 2013-2014, Hispanics/Latinos receiving HIV medical care in the United States had many unmet needs for ancillary services. The most prevalent unmet needs were for dental care and eye or vision care; these services are essential because many persons living with HIV have oral or eye conditions that require specialized care. Hispanics/Latinos with unmet needs for services often did not know how to get them, were ineligible for, perceived themselves to be ineligible for, or were denied these services.

For many persons living with HIV, ancillary services are critical for adhering to HIV treatment and achieving viral suppression (2). Hispanic/Latino men and women in HIV medical care have higher levels of homelessness and lower levels of health insurance coverage than their non-Hispanic/ Latino counterparts, and nearly three quarters of Hispanic/ Latino women in HIV medical care and half of Hispanic/ Latino men are living at or below the federal poverty level (4). This analysis indicates that Hispanic/Latino persons of all ages and sexual orientations have substantial unmet needs for subsistence services (e.g., food or nutrition, shelter or housing, and transportation assistance). These needs might lead to poorer HIV treatment outcomes; Hispanics/Latinos in HIV medical care are less likely than non-Hispanic whites to be virally suppressed (4). Previous research suggests Hispanics/ Latinos are more likely to delay entry into HIV medical care because of unmet transportation, shelter, or food service needs, and to enter into care with more advanced HIV disease than non-Hispanics/Latinos (5)

The National HIV/AIDS Strategy specifies goals for improving health outcomes among persons living with HIV by increasing access to basic needs, and reducing racial and ethnic HIV-related disparities (6). Addressing unmet needs for ancillary services among Hispanics/Latinos living with HIV can help reach the National HIV/AIDS Strategy goals of reducing health disparities, increasing access to care, and improving health outcomes for persons living with HIV. 
TABLE 1. Percentage of Hispanics/Latinos receiving outpatient HIV medical care with unmet needs for ancillary services,* by demographic characteristic - Medical Monitoring Project, United States, 2013-2014

\begin{tabular}{|c|c|c|c|c|c|c|c|c|}
\hline & & Dental care & $\begin{array}{c}\text { Eye or } \\
\text { vision care }\end{array}$ & $\begin{array}{c}\text { Food or } \\
\text { nutrition }\end{array}$ & $\begin{array}{c}\text { Transportation } \\
\text { assistance }\end{array}$ & $\begin{array}{c}\text { Shelter or } \\
\text { housing }\end{array}$ & $\begin{array}{l}\text { HIV peer group } \\
\text { support } \\
\end{array}$ & $\begin{array}{c}\text { Mental } \\
\text { health care } \\
\end{array}$ \\
\hline Demographic characteristic & Total & $\%^{\dagger}\left(95 \% \mathrm{Cl}^{\S}\right)$ & $\%^{\dagger}\left(95 \% \mathrm{Cl}^{\S}\right)$ & $\%^{\dagger}\left(95 \% \mathrm{Cl}^{\S}\right)$ & $\%^{\dagger}\left(95 \% \mathrm{Cl}^{\S}\right)$ & $\%^{\dagger}\left(95 \% \mathrm{Cl}^{\S}\right)$ & $\%^{\dagger}\left(95 \% \mathrm{Cl}^{\S}\right)$ & $\%^{\dagger}\left(95 \% \mathrm{Cl}^{\S}\right)$ \\
\hline \multicolumn{9}{|l|}{ Age (yrs) } \\
\hline $18-29$ & 197 & $25(16-33)$ & $16(9-23)$ & $17(11-22)$ & $10(5-14)$ & $14^{9}(9-18)$ & $10^{9}(6-14)$ & $-^{\dagger+}$ \\
\hline $30-39$ & 435 & $31^{9}(26-36)$ & $21(17-26)$ & 19 (14-23) & $9(5-12)$ & $11^{9}(8-14)$ & $11^{9}(8-14)$ & $8(5-11)$ \\
\hline $40-49$ & 746 & $24(19-28)$ & $24(21-28)$ & $16^{\mathbb{n}(13-18)}$ & $10(8-13)$ & $7(5-10)$ & $7(5-8)$ & $5(3-7)$ \\
\hline$\geq 50$ & 1,019 & $21(17-26)$ & $20(17-23)$ & $12(10-14)$ & $9(7-11)$ & $5(3-7)$ & $6(4-7)$ & $6(4-7)$ \\
\hline \multicolumn{9}{|l|}{ Sexual orientation/behavior $\S^{\S}$} \\
\hline Men who have sex with men & 1,072 & $25(21-28)$ & $22(19-24)$ & $14(12-17)$ & $8(6-9)$ & $8(6-11)$ & $9(7-11)$ & $7(5-9)$ \\
\hline Men who have sex with women only & 686 & $25(19-30)$ & $22(18-25)$ & $15(12-17)$ & $12^{* *}(9-15)$ & $8(6-10)$ & $5^{* *}(4-7)$ & $4^{* *}(3-6)$ \\
\hline Women who have sex with men & 559 & $22(16-27)$ & $21(16-26)$ & $15(12-19)$ & $10(7-13)$ & $7(4-9)$ & $7(5-8)$ & $6(4-8)$ \\
\hline Other & 80 & $28(17-40)$ & $19(11-27)$ & $-{ }^{+\dagger}$ & $12(5-20)$ & - +t & $9(4-14)$ & - $^{+\dagger}$ \\
\hline Total & & $24(20-28)$ & $21(19-24)$ & $15(13-17)$ & $9(8-11)$ & $8(6-9)$ & $7(6-8)$ & $6(5-7)$ \\
\hline
\end{tabular}

Abbreviations: $\mathrm{Cl}=$ confidence interval. $\mathrm{HIV}=$ human immunodeficiency virus.

* Ancillary services are defined as services that support retention in primary HIV medical care and assist with day-to-day living.

† Percentages are weighted percentages.

$\S \mathrm{Cls}$ incorporate weighted percentages.

I P-value $<0.05$ in comparison to reference group ( $>50$ year olds).

** P-value $<0.05$ in comparison to reference group (men who have sex with men).

${ }^{\dagger+}$ Estimates suppressed because coefficient of variation for the estimate was $\geq 30 \%$.

$\S \S$ Sexual orientation/behavior was defined by gender of participants'sex partners or, if no sexual activity was reported, by participants'sexual orientation. Categories are mutually exclusive.

TABLE 2. Reasons for unmet needs for ancillary services* among Hispanics/Latinos receiving outpatient HIV medical care — Medical Monitoring Project, United States, 2013-2014

\begin{tabular}{|c|c|c|c|c|c|c|c|}
\hline & & $\begin{array}{l}\text { Didn't know how } \\
\text { to get service }\end{array}$ & $\begin{array}{l}\text { In process of } \\
\text { getting service }\end{array}$ & $\begin{array}{l}\text { Not eligible or } \\
\text { denied services }\end{array}$ & $\begin{array}{l}\text { Money or insurance } \\
\text { issues }\end{array}$ & $\begin{array}{l}\text { Psychological } \\
\text { barriers }\end{array}$ & $\begin{array}{c}\text { Service Is } \\
\text { unavailable }\end{array}$ \\
\hline Service & Total & $\%^{\dagger}\left(95 \% \mathrm{Cl}^{\S}\right)$ & $\%^{\dagger}\left(95 \% \mathrm{Cl}^{\S}\right)$ & $\%^{\dagger}\left(95 \% \mathrm{Cl}^{\S}\right)$ & $\%^{\dagger}\left(95 \% \mathrm{Cl}^{\S}\right)$ & $\%^{\dagger}\left(95 \% \mathrm{Cl}^{\S}\right)$ & $\%^{\dagger}\left(95 \% \mathrm{Cl}^{\S}\right)$ \\
\hline Dental care & 556 & $13(10-16)$ & $31(26-36)$ & $9(6-12)$ & $16(10-21)$ & $11(8-14)$ & $4(2-5)$ \\
\hline Eye or vision care & 529 & $22(18-26)$ & $36(30-42)$ & $5(3-7)$ & $14(10-18)$ & $8(6-10)$ & $5(2-8)$ \\
\hline Food or nutrition & 367 & $42(34-49)$ & $15(10-19)$ & $15(10-19)$ & - & - & $8(5-11)$ \\
\hline $\begin{array}{l}\text { Transportation } \\
\text { assistance }\end{array}$ & 231 & $44(36-52)$ & $8(4-13)$ & $21(14-28)$ & - & - & $14(8-21)$ \\
\hline Shelter or housing & 181 & $25(19-32)$ & $22(16-29)$ & $28(21-36)$ & - & - & - \\
\hline $\begin{array}{l}\text { HIV peer group } \\
\text { support }\end{array}$ & 185 & $43(35-51)$ & $9(4-13)$ & - & -9 & $9(4-14)$ & $18(11-24)$ \\
\hline Mental health care & 147 & $25(18-32)$ & $25(16-34)$ & - & - & $19(12-26)$ & - \\
\hline
\end{tabular}

Abbreviations: $\mathrm{Cl}=$ confidence interval. $\mathrm{HIV}=$ human immunodeficiency virus.

* Ancillary services are defined as services that support retention in primary HIV medical care and assist with day-to-day living.

† Percentages are weighted percentages.

$\S$ Cls incorporate weighted percentages.

I Estimates suppressed because coefficient of variation for the estimate was $\geq 30 \%$.

In this analysis, approximately half of Hispanics/Latinos in HIV care and with unmet needs for subsistence services did not receive these services because of real or perceived ineligibility or because they did not know how to get services. In some cases, this might be related to immigration status, because just under $40 \%$ of Hispanics/Latinos in HIV care in the United States are foreign born (7). In previous research, Hispanic/ Latino immigrants living with HIV cited inadequate knowledge about available services as obstacles to receiving HIV care and often held erroneous beliefs about service eligibility for undocumented persons (8). Case managers might consider providing targeted support to Hispanic/Latino clients who are navigating service availability and eligibility, especially in complicated immigration situations.

For persons living with HIV in the United States, the Ryan White HIV/AIDS Program is the primary funder of ancillary services, through grants to states, territories, and communitybased organizations that serve approximately half a million persons each year. The program provides services for all persons living with HIV infection in the United States regardless of immigration status, including nearly 113,000 Hispanics/ Latinos in 2014 (9). Co-locating ancillary services with routine HIV medical care using a medical home model is a hallmark 


\section{Summary}

What is already known about this topic?

Ancillary services can help persons living with HIV access HIV medical care, adhere to HIV treatment, and achieve HIV viral suppression.

What is added by this report?

During 2013-2014, Hispanics/Latinos receiving HIV medical care in the United States reported many unmet needs for ancillary services, including dental care (an estimated 24\%), eye or vision care (21\%), and subsistence services such as assistance with food and nutrition (15\%) and transportation (9\%). Most of those with unmet needs for ancillary services did not know how to access or were ineligible for, perceived themselves to be ineligible for, or were denied these services.

What are the implications for public health practice?

Increasing awareness of the availability of ancillary services might help improve the health of Hispanics/Latinos living with HIV and reduce HIV-related health disparities.

of the program, and might increase access to these services for persons in HIV medical care (10).

The findings in this report are subject to at least four limitations. First, the analysis was limited to Hispanics/ Latinos in HIV care, and results might not be generalizable to Hispanics/Latinos living with HIV who are not in HIV medical care, among whom unmet needs for services might be more prevalent. Second, needs and eligibility for ancillary services are self-reported and were not objectively verified. Third, prevalence of unmet needs likely varies geographically. Local analyses might provide targeted information for resource allocation and policy decisions. Finally, MMP's response rate was $55 \%$ at the patient level. Although the data were adjusted to minimize nonresponse bias based on known characteristics of sampled facilities and patients, the possibility of residual nonresponse bias exists.

Hispanics/Latinos receiving HIV medical care in the United States have considerable unmet needs for ancillary services among all age and sexual orientation/behavior categories. The majority of those with unmet needs for ancillary services did not know how to access or were ineligible for, perceived themselves to be ineligible for, or were denied these services. Increasing awareness of available ancillary services might help improve the health of Hispanics/Latinos living with HIV and reduce HIV-related health disparities.
${ }^{1}$ Division HIV/AIDS Prevention, National Center for HIV/AIDS, Viral Hepatitis, STD, and TB Prevention, CDC; ${ }^{2}$ Oak Ridge Institute for Science and Education, Oak Ridge, Tennessee.

Corresponding author: Lauren C. Korhonen,xgc9@cdc.gov, 404-639-6286.

\section{References}

1. CDC. Diagnoses of HIV infection in the United States and dependent areas, 2014. HIV Surveillance Report, vol. 26. Atlanta, GA: US Department of Health and Human Services, CDC; 2015. https://www.cdc.gov/hiv/pdf/ library/reports/surveillance/cdc-hiv-surveillance-report-us.pdf

2. Conviser R, Pounds MB. The role of ancillary services in client-centred systems of care. AIDS Care 2002;14(Suppl 1):S119-31. http://dx.doi. org/10.1080/09540120220150018

3. CDC. Behavioral and clinical characteristics of persons receiving medical care for HIV infection-Medical Monitoring Project, United States, 2013 Cycle (June 2013-May 2014). 2016. HIV Surveillance Report no. 16. http://www.cdc.gov/hiv/pdf/library/reports/surveillance/cdchiv-hssr-mmp-2013.pdf

4. Beer L, Mattson CL, Bradley H, Skarbinski J; Medical Monitoring Project. Understanding cross-sectional racial, ethnic, and gender disparities in antiretroviral use and viral suppression among HIV patients in the United States. Medicine (Baltimore) 2016;95:e3171. http://dx.doi. org/10.1097/MD.0000000000003171।

5. Dennis AM, Napravnik S, Seña AC, Eron JJ. Late entry to HIV care among Latinos compared with non-Latinos in a southeastern US cohort. Clin Infect Dis 2011;53:480-7. http://dx.doi.org/10.1093/cid/cir434

6. The White House Office of National AIDS Policy. National HIV/AIDS Strategy for the United States: Updated to 2020. Washington, DC: White House Office of National AIDS Policy; 2015. https://www.aids. gov/federal-resources/national-hiv-aids-strategy/nhas-update.pdf

7. Myers TR, Lin X, Skarbinski J. Antiretroviral therapy and viral suppression among foreign-born HIV-infected persons receiving medical care in the United States: a complex sample, cross-sectional survey. Medicine (Baltimore) 2016;95:e3051. http://dx.doi.org/10.1097/ MD.0000000000003051

8. Shedlin MG, Shulman L. Qualitative needs assessment of HIV services among Dominican, Mexican and Central American immigrant populations living in the New York City area. AIDS Care 2004;16:434-45. http://dx.doi.org/10.1080/09540120410001683376

9. Health Resources and Services Administration. Ryan White HIV/AIDS program annual client-level data report 2014. Rockville, MD: US Department of Health and Human Services, Health Resources and Services Administration; 2015. http://hab.hrsa.gov/data/servicesdelivered/ 2014RWHAPDataReport.pdf

10. Beane SN, Culyba RJ, DeMayo M, Armstrong W. Exploring the medical home in Ryan White HIV care settings: a pilot study. J Assoc Nurses AIDS Care 2014;25:191-202. http://dx.doi.org/10.1016/j. jana.2013.10.007 